\section{Stem cell yield and transplantation in transplant-eligible newly diagnosed multiple myeloma patients receiving daratumumab plus bortezomib/thalidomide/dexamethasone in the phase III CASSIOPEIA study}

High-dose therapy (HDT) followed by autologous stem cell transplantation (ASCT) is the standard of care for transplant-eligible patients with newly diagnosed multiple myeloma (NDMM) ${ }^{1,2}$ An adequate stem cell yield is essential for timely hematopoietic reconstitution after ASCT. ${ }^{3}$ Daratumumab is a human immunoglobulin (Ig) GK monoclonal antibody targeting CD38 with a direct on-tumor ${ }^{4-6}$ and immunomodulatory mechanism of action..$^{7-9}$ Multiple studies have demonstrated the clinical benefits of adding daratumumab to standard-of-care regimens or as monotherapy across lines of therapy in multiple myeloma. ${ }^{10}$

The phase III CASSIOPEIA study investigated daratumumab plus the standard-of-care regimen bortezomib/thalidomide/dexamethasone (D-VTd) versus bortezomib/thalidomide/dexamethasone (VTd) in ASCTeligible patients with NDMM. ${ }^{11}$ In part 1 of the study, patients received induction, ASCT, and consolidation therapy, which was followed by part 2 of the study where patients with a partial response or better after consolidation were re-randomized to receive maintenance therapy or observation. Here we report stem cell yield/harvest and transplantation results in part 1 of CASSIOPEIA.

The study design and eligibility criteria of CASSIOPEIA have been previously reported (clinicaltrials gov. Identifier: NCT02541383) (Figure 1). ${ }^{11}$ Briefly, eligible patients were 18 to 65 years of age, had NDMM, had an Eastern Cooperative Oncology Group performance status of 0 to 2, and were candidates for HDT and ASCT. Major exclusion criteria included the following: hemoglobin concentration $<7.5 \mathrm{~g} / \mathrm{dL}$; absolute neutrophil count $<1.0 \times 10^{9} / \mathrm{L}$; platelet count $\leq 50 \times 10^{9} / \mathrm{L}$ (or $<70 \times 10^{9} / \mathrm{L}$ if $<50 \%$ of bone marrow nucleated cells were plasma cells); aspartate aminotransferase and alanine aminotransferase levels $>2.5$ times the upper limit of normal (ULN); total bilirubin level $>1.5$ times ULN; calculated creatinine clearance $<40$ $\mathrm{mL} / \mathrm{min}$; corrected serum calcium concentration $>14$ $\mathrm{mg} / \mathrm{dL}$ (3.5 mmol/L); primary amyloidosis, monoclonal gammopathy of undetermined significance, smoldering multiple myeloma, solitary plasmacytoma, or Waldenström macroglobulinemia; previous systemic therapy or stem cell transplantation for any plasma cell dyscrasia; and grade $\geq 2$ peripheral neuropathy or grade $\geq 2$ neuropathic pain. All patients provided written informed consent; the trial was approved by Institutional Review Board/ethics committees at each site and was conducted in accordance with the Declaration of Helsinki, Good Clinical Practices, and applicable regulatory requirements.

Following induction, patients underwent stem cell

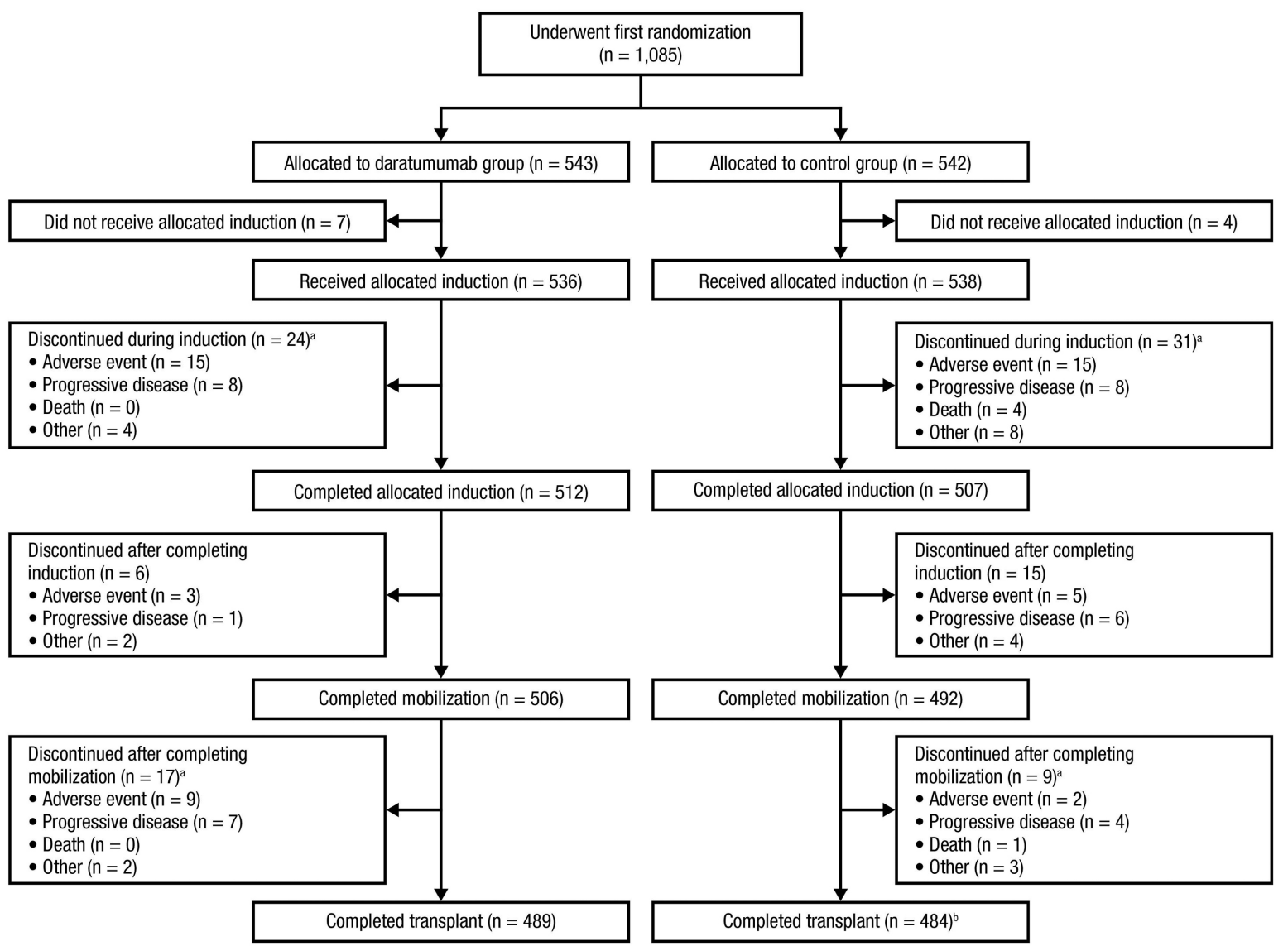

Figure 1. CONSORT diagram for the CASSIOPEIA study. The study flow diagram is shown for the CASSIOPEIA study from first randomization through completion of autologous stem cell transplant. The daratumumab group received daratumumab/bortezomib/thalidomide/dexamethasone; the control group received

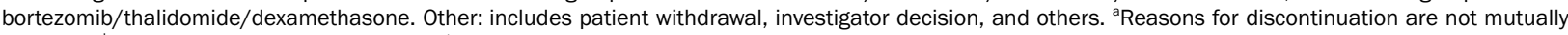
exclusive. 'one patient had successful $\mathrm{CD} 34^{+}$stem cell collection without any previous mobilization treatment. 
Table 1. Stem cell mobilization, harvesting, and transplantation.

\begin{tabular}{|c|c|c|c|}
\hline & D-VId & VId & $P$ \\
\hline Patients with stem cell mobilization & $\mathrm{N}=506$ & $\mathrm{~N}=492$ & \\
\hline \multicolumn{4}{|l|}{ PBSC mobilizing agents, $\mathrm{n}(\%)^{\mathrm{a}}$} \\
\hline Cyclophosphamide/G-CSF & $506(100)$ & $492(100)$ & \\
\hline Plerixafor & $110(21.7)$ & $39(7.9)$ & $<0.0001^{b}$ \\
\hline PBSC apheresis performed, $n(\%)$ & $504(99.6)^{c}$ & $490(99.6)^{d}$ & $>0.999^{\mathrm{b}}$ \\
\hline Patients with PBSC apheresis performed & $\mathrm{N}=504$ & $\mathrm{~N}=490$ & \\
\hline Number of days of apheresis, mean [SD] (range) & $\begin{array}{c}1.9[0.92] \\
(1-6)\end{array}$ & $\begin{array}{c}1.4[0.67] \\
(1-4)\end{array}$ & $<0.0001^{\mathrm{e}}$ \\
\hline Number of days of apheresis, $\mathrm{n}(\%)$ & & & $<0.0001^{\mathrm{f}}$ \\
\hline 1 & $184(36.5)$ & $327(66.7)$ & \\
\hline 2 & $204(40.5)$ & $125(25.5)$ & \\
\hline 3 & $91(18.1)$ & $32(6.5)$ & \\
\hline 4 & $18(3.6)$ & $6(1.2)$ & \\
\hline 5 & $4(0.8)$ & 0 & \\
\hline 6 & $3(0.6)$ & 0 & \\
\hline \multicolumn{4}{|c|}{ Total number of CD34 ${ }^{+}$stem cells collected $\left(10^{6} / \mathrm{kg}\right)$ among patients with PBSC apheresis performed } \\
\hline \multirow[t]{2}{*}{ Mean [SD] (range) } & $6.7[2.63]$ & $10.0[5.25]$ & $<0.0001^{\mathrm{e}}$ \\
\hline & $(0.5-18.7)$ & $(2.2-36.9)$ & \\
\hline$\geq 2 \times 10^{6} / \mathrm{kg}, \mathrm{n}(\%)$ & $501(99.4)$ & $490(100)$ & $0.2494^{\mathrm{b}}$ \\
\hline$\geq 4 \times 10^{6} / \mathrm{kg}, \mathrm{n}(\%)$ & $444(88.1)$ & $470(95.9)$ & $<0.0001^{\mathrm{b}}$ \\
\hline$\geq 5 \times 10^{6} / \mathrm{kg}, \mathrm{n}(\%)$ & $380(75.4)$ & $434(88.6)$ & $<0.0001^{\mathrm{b}}$ \\
\hline Patients who underwent transplantation, $\mathrm{n}(\%)$ & $489(97.0)$ & $484(98.8)$ & $0.0758^{\mathrm{b}}$ \\
\hline \multirow[t]{2}{*}{ Number of CD34 $4^{+}$stem cells transplanted $\left(10^{6} / \mathrm{kg}\right)$, Mean [SD] (range) } & $3.6[1.59]$ & $5.0[2.80]$ & $<0.0001^{\mathrm{e}}$ \\
\hline & $(0.5-12.6)$ & $(1.2-23.3)$ & \\
\hline
\end{tabular}

Percentages were calculated with $\mathrm{N}$ in each group as the denominator. ${ }^{\mathrm{a}}$ Several PBSC mobilizing agents were possible. ${ }^{\mathrm{b}} P$-value calculated from Fisher's exact test. ${ }^{\mathrm{c} B o n e}$ marrow harvest was performed for one patient in the D-VTd arm and no patients in the VTd arm. No patients had only bone marrow collection. The D-VTd patient received a stem cell collection from bone marrow in addition to apheresis from peripheral blood. Here both numbers are summed as a total of CD34 $4^{+}$stem cells collected from this patient. ${ }^{\mathrm{d} B a s e d}$ on available information from the investigator, one patient in the VTd arm had successful CD34 ${ }^{+}$stem cell collection without a record of mobilization treatment. However, unrecorded mobilization likely occurred, although details are undocumented. ${ }^{e} P$-value calculated from two-sample $t$-test. ${ }^{f} P$-value calculated from Cochran-Armitage trend test. D-Vtd: daratumumab/bortezomib/thalidomide/dexamethasone;Vtd: bortezomib/thalidomide/dexamethasone; PBSC: peripheral blood stem cell; G-CSF: granulocyte colony-stimulating factor; SD: standard deviation.

mobilization with cyclophosphamide (recommended dose, $3 \mathrm{~g} / \mathrm{m}^{2}$ ) and granulocyte colony-stimulating factor (G-CSF) (recommended dose, $10 \mu \mathrm{g} / \mathrm{kg} /$ day until the last day of the collection for a maximum of 10 days) after cycle 4 . The recommended cyclophosphamide dose $\left(3 \mathrm{~g} / \mathrm{m}^{2}\right)$ was not mandatory and varied by region (e.g., more patients received $2 \mathrm{~g} / \mathrm{m}^{2}$ in the Netherlands and Belgium, while more received $3 \mathrm{~g} / \mathrm{m}^{2}$ in France). Plerixafor use was permitted per institutional practice in case of failure. Peripheral blood stem cells were harvested based on response to mobilization. Patients underwent conditioning with intravenous melphalan $200 \mathrm{mg} / \mathrm{m}^{2}$ prior to ASCT. Per protocol, sufficient stem cells should be harvested to enable multiple transplants, in accordance with institutional standards. Cell counting after harvesting was conducted locally, per institutional practice. Consolidation therapy was initiated after hematopoietic reconstitution, but not earlier than 30 days after transplantation. Intergroupe Francophone du Myélome and Janssen statisticians were involved in all stages of the study and data analysis.

A total of 1,085 patients were randomized to D-VTd $(n=543)$ or VTd $(n=542)$ (Figure 1). Results for stem cell mobilization, harvesting, and transplantation are presented in Table 1. At the clinical cutoff of June 19, 2018, among those undergoing induction (D-VTd, n=536; VTd, $\mathrm{n}=538), 506(94.4 \%)$ patients in the D-VTd group and $492(91.4 \%)$ patients in the VTd group received
cyclophosphamide/G-CSF; 504 (94.0\%) and 490 (91.1\%) patients, respectively, underwent stem cell harvesting. Plerixafor was administered in the course of stem cell mobilization to 110 patients $(21.7 \%$ of the 506 patients who underwent mobilization) in the $\mathrm{D}-\mathrm{VTd}$ group versus 39 patients $(7.9 \%$ of the 492 patients who underwent mobilization) in the VTd group $(P<0.0001)$. One patient who received VTd had no record of mobilization treatment but had successful collection of $\mathrm{CD} 34^{+}$cells from peripheral blood in 2 consecutive days of apheresis; this patient received HDT with stem cell transplant with engraftment. One patient in the D-VTd group had stem cells collected from bone marrow in addition to apheresis from peripheral blood. Five patients (D-VTd, $n=2 ; \mathrm{VTd}$, $\mathrm{n}=3$ ) who received mobilizing agents did not undergo stem cell harvesting; of these, mobilization failure was noted in three patients (D-VTd, $n=2 ; \mathrm{VTd}, \mathrm{n}=1)$. The two patients in the D-VTd group who failed mobilization underwent two mobilization procedures and failed both. The single patient in the VTd group who failed mobilization did not have a second procedure. The remaining two patients in the VTd group who received mobilizing agents did not undergo stem cell harvest and discontinued treatment due to death $(n=1$; serious adverse event of large intestine perforation with a history of sigmoid diverticulosis) or disease progression $(n=1)$.

The mean number of days of apheresis were 1.9 for $\mathrm{D}$ VTd versus 1.4 for VTd $(P<0.0001$; Table 1). Apheresis 
Table 2. Stem cell transplantation outcomes.

\begin{tabular}{|c|c|c|c|}
\hline Patients with transplantation & $\begin{array}{l}D-V / d \\
N=489\end{array}$ & $\begin{array}{l}\text { VId } \\
N=484\end{array}$ & $P$ \\
\hline Patients with hematopoietic reconstitution, $\mathrm{n}(\%)$ & $488(99.8)$ & $482(99.6)$ & $0.6227^{\mathrm{a}}$ \\
\hline Platelet recovery (achieving sustained platelets $>20,000$ cells $/ \mathrm{mm}^{3}$ without transfusion), $\mathrm{n}(\%)$ & $413(84.5)$ & $361(74.6)$ & $0.0001^{\mathrm{a}}$ \\
\hline $\begin{array}{l}\text { Number of days to achieve sustained platelets }>20,000 \text { cells } / \mathrm{mm}^{3} \text { without transfusion, } \\
\text { mean [SD] (range) }\end{array}$ & $14.9[5.38](2-56)$ & $13.6[4.64](1-47)$ & $0.0004^{b}$ \\
\hline Neutrophil recovery (achieving sustained absolute neutrophil counts $>500$ cells $/ \mathrm{mm}^{3}$ ), n (\%) & $475(97.1)$ & $474(97.9)$ & $0.5363^{\mathrm{a}}$ \\
\hline $\begin{array}{l}\text { Number of days to achieve sustained absolute neutrophil counts }>500 \text { cells } / \mathrm{mm}^{3} \text {, } \\
\text { mean [SD] (range) }\end{array}$ & $14.4[4.07](6-54)$ & $13.7[4.20](4-43)$ & $0.0155^{b}$ \\
\hline
\end{tabular}

D-Vtd: daratumumab/bortezomib/thalidomide/dexamethasone; Vtd: bortezomib/thalidomide/dexamethasone; SD: standard deviation. ${ }^{2} P$-value calculated from Fisher's exact test. $P$-value calculated from two-sample $t$-test.

lasting 4-6 days occurred in $5.0 \%$ (25 of 504) and $1.2 \%$ (six of 490) of patients in the D-VTd and VTd groups who received apheresis. The mean number of $\mathrm{CD} 34^{+}$ stem cells collected was lower for patients receiving DVTd versus VTd $\left(6.7 \times 10^{6} / \mathrm{kg}\right.$ vs. $10.0 \times 10^{6} / \mathrm{kg}$, respectively; $P<0.0001$; Table 1). Nevertheless, among those who received apheresis, a similar percentage of D-VTd-treated patients and VTd-treated patients underwent ASCT (97.0\% vs. $98.8 \%$, respectively; $P=0.0758$; Table 1). Of the patients who completed mobilization without receiving transplant, the most common reasons for discontinuation were adverse events in the D-VTd group (D-VTd, $\mathrm{n}=8$; VTd, $\mathrm{n}=2$ ) and disease progression in the VTd group (D-VTd, n=7; VTd, n=4).

ASCT was undergone by 489 patients in the D-VTdgroup and 484 patients in the VTd group. The mean number of CD34+ stem cells transplanted was $3.6 \times 10^{6} / \mathrm{kg}$ in the D-VTd group compared with $5.0 \times 10^{6} / \mathrm{kg}$ in the VTd group $(P<0.0001$; Table 1$)$. Hematopoietic reconstitution rates were high and similar in transplanted patients receiving D-VTd and VTd $(99.8 \%$ vs. $99.6 \%$, respectively; $P=0.6227$; Table 2 ). The mean (standard deviation) time to achieve sustained platelet counts $>20,000$ cells $/ \mathrm{mm}^{3}$ without transfusion was 14.9 days for D-VTd versus 13.6 days for VTd $(P=0.0004)$, and the mean time to achieve sustained absolute neutrophil counts $>500$ cells $/ \mathrm{mm}^{3}$ was 14.4 days for D-VTd versus 13.7 days for VTd $(P=0.0155$; Table 2). Despite the greater mean number of days needed to achieve sustained platelet counts $>20,000$ cells $/ \mathrm{mm}^{3}$ without transfusion and absolute neutrophil counts $>500$ cells $/ \mathrm{mm}^{3}$ with D-VTd versus VTd, the percentage of patients who achieved platelet recovery was higher with D-VTd $(84.5 \%$ vs. $74.6 \% ; P=0.0001)$ and the percentages of patients who achieved neutrophil recovery were similar between the two treatment groups $(97.1 \%$ vs. $97.9 \%$; $P=0.5363$; Table 2).

Although there was lower stem cell yield and higher plerixafor use in the D-VTd group, the addition of daratumumab to VTd did not impair the feasibility and safety of performing transplant or the success of engraftment post transplant. Potential reasons why daratumumab results in lower stem cell yield in this study are unknown; however, daratumumab may possibly cause some degree of interference through an unknown mechanism, as $\mathrm{CD}_{3} 4^{+}$committed stem cells express a low level of CD38. ${ }^{12}$ Factors that have previously been demonstrated to impact yield, such as age, sex and weight, are not specifically associated with daratumumab or daratumumab-treated patients. ${ }^{13,14}$ Close monitoring and early implementation of plerixafor could be considered for patients with risk factors for lower yield. ${ }^{15}$
Differences between treatment arms reached statistical significance for several parameters of stem cell mobilization, harvesting, and transplant. However, these differences were ultimately not clinically relevant, as posttransplant hematopoietic reconstitution was nearly identical $(99.8 \%$ vs. $99.6 \%)$ in both treatment arms. Transplantation should be managed on an individual basis and with clinical judgment considering the overall situation of the patient.

In conclusion, the addition of daratumumab to VTd during induction therapy did not impair the feasibility and safety of transplantation with successful engraftment, even though stem cell yield was lower with DVTd. Combined with the primary efficacy and safety data reported previously, D-VTd is considered a valid treatment option for patients with NDMM who are transplant-eligible.

Cyrille Hulin, ${ }^{1}$ Fritz Offner, ${ }^{2}$ Philippe Moreau, ${ }^{3}$ Murielle Roussel, ${ }^{4}$ Karim Belhadj, ${ }^{5}$ Lotfi Benboubker, ${ }^{6}$ Denis Caillot, ${ }^{7}$ Thierry Facon, ${ }^{8}$ Laurent Garderet, ${ }^{9}$ Frédérique Kuhnowski, ${ }^{10}$ Anne-Marie Stoppa, ${ }^{11}$ Brigitte Kolb, ${ }^{12}$ Mourad Tiab, ${ }^{13}$ Kon-Siong Jie, ${ }^{14}$ Matthijs Westerman, ${ }^{15}$ Jérôme Lambert, ${ }^{16}$ Lixia Pei, ${ }^{17}$ Veronique Vanquickelberghe, ${ }^{18}$ Carla de Boer, ${ }^{19}$ Jessica Vermeulen, ${ }^{19}$ Tobias Kampfenkel, ${ }^{19}$ Pieter Sonneveld, ${ }^{20}$ and Niels W.C.J. van de Donk ${ }^{21}$ on behalf of the Intergroupe Francophone du Myélome (IFM) and DutchBelgian Cooperative Trial Group for Hematology Oncology (HOVON)

${ }^{1}$ Department of Hematology, Hôpital Haut-Lévêque, University Hospital Bordeaux, Pessac, France; ${ }^{2}$ Hematology, University Hospital Ghent, Ghent, Belgium; ${ }^{3}$ Service d'Hématologie Clinique, University Hospital Hôtel-Dieu, Nantes, France; ${ }^{4}$ Service d'Hématologie Clinique, IUC Oncopole, Toulouse, France; ${ }^{5}$ Hémopathies Lymphoïdes, Hôpital Henri Mondor, Creteil, France; ${ }^{6} \mathrm{CHU}$ de Tours, Hôpital de Bretonneau, Tours, France; ${ }^{7} \mathrm{CHU}$ Dijon, Hôpital Du Bocage, Dijon, France; ${ }^{8}$ University of Lille, CHU Lille, Service des Maladies du Sang, Lille, France; 'Sorbonne Université, INSERM, UMR_S 938, Centre de Recherche Saint-Antoine, Team Proliferation and Differentiation of Stem Cells, Assistance Publique-Hôpitaux de Paris, Hôpital Pitié Salpetrière, Département d'Hématologie, Paris, France; ${ }^{10}$ Institut Curie Paris, Paris, France; ${ }^{11}$ Institut Paoli-Calmettes, Marseille, France; ${ }^{12} \mathrm{CHU}$ de Reims, Hôpital Robert Debré, Reims, France; ${ }^{13} \mathrm{CHD}$ Vendée, La Roche-sur-Yon, France; ${ }^{14}$ Zuyderland MC, Sittard, the Netherlands; ${ }^{15}$ Northwest Clinics, Alkmaar, the Netherlands; ${ }^{16}$ Biostatistical Department, Hôpital Saint Louis, Paris, France; ${ }^{17} J a n s s e n$ Research \& Development, LLC, Raritan, NJ, USA; ${ }^{18}$ Janssen Research \& Development, Beerse, Belgium; ${ }^{19} \mathrm{Janssen}$ Research \& Development, LLC, Leiden, the Netherlands; ${ }^{20}$ Erasmus University Medical Center Cancer Institute, Rotterdam, the Netherlands and ${ }^{21}$ Amsterdam UMC, Vrije Universiteit Amsterdam, Department of Hematology, Amsterdam, the Netherlands 
Correspondence:

CYRILLEHULIN - cyrille.hulin@chu-bordeaux.fr

doi:10.3324/haematol.2020.261842

Received: June 9, 2020.

Accepted: February 18, 2021.

Pre-published: March 4, 2021.

Disclosures: $\mathrm{CH}$ has received honoraria from Celgene, Janssen, Amgen, and Takeda; and travel, accommodations, and expenses from Celgene, Janssen, and Amgen. PM has received honoraria from and served as a consultant or in an advisory role for Celgene, Janssen, Amgen, and AbbVie. MR has received research funding from Amgen, Janssen, Takeda, and Celgene; travel, accommodation, and expenses from Amgen, Janssen, Celgene, Takeda, and Sanofi; and lecture fees from Amgen, Janssen, Celgene, and Takeda. KB has received personal fees from Celgene, Amgen, Takeda, and Janssen. TF has severed as a consultant or in an advisory role, participated in a speakers' bureau, and received travel, accommodations, or expenses from Janssen. $L G$ has served as a consultant or in an advisory role for Amgen, Celgene, Takeda, Novartis, and Janssen. A-MS has received honoraria from Janssen, Celgene, Amgen, Novartis, and Takeda. LP, VV, CB, JV and TK are emplovees of Janssen Research \& Development. $P S$ has received research funding and/or honoraria from Amgen, Celgene, Janssen, Karyopharm, and Bristol Myers Squibb. NWCJD has served as a consultant or in an advisory role for Janssen, Celgene, Bristol Myers Squibb, Amgen, Novartis, Bayer, Servier, and Takeda; and has received research funding from Janssen, Celgene, Bristol Myers Squibb, Amgen, and Novartis. FO, LB, DC, BK, MT, K-SJ, $M W$ and $J L$ have nothing to disclose.

Contributions: $C H, F O, P M, M R, K B, L B, D C, T F, L G, F K$, $A-M S, B K, M T, K-S J, M W, P S$, and NWCJvdD enrolled patients and collected data; NWCJvdD, JL, LP, VV, CdB, JV, and TK analyzed the data. All authors interpreted the data, contributed to the drafting and critical review of the manuscript, and approved the final version for submission. Janssen Research \& Development, LLC, the Intergroupe Francophone du Myélome (IFM), and the Dutch-Belgian Cooperative Trial Group for Hematology Oncology (HOVON) collaborated to design the study.

Acknowledgments: the Intergroupe Francophone du Myélome (IFM) and Dutch-Belgian Cooperative Trial Group for Hematology Oncology (HOVON) sponsored this trial. This analysis was funded by Janssen Global Services, LLC. The authors, IFM, HOVON, and Janssen gratefully acknowledge the valued scientific contribution from $D r$. Brigitte Kolb. Dr. Kolb passed away on the 5th of October, 2020, and will be dearly missed by the research teams that she contributed to or led. The authors would also like to thank the patients who participated in this study and their families, study investigators, staff members at each study site, and staff members involved in data collection and analyses. Medical writing and editorial support were provided by Kimberly Carmony, PhD, and Grace Wang, PharmD, of MedErgy, and were funded by Janssen Global Services, LLC.

\section{References}

1. Moreau P, San Miguel J, Sonneveld P, et al. Multiple myeloma: ESMO Clinical Practice Guidelines for diagnosis, treatment and follow-up. Ann Oncol. 2017;28(Suppl_4):iv52-iv61.

2. Mikhael J, Ismaila N, Cheung MC, et al. Treatment of multiple myeloma: ASCO and CCO joint clinical practice guideline. J Clin Oncol. 2019;37(14):1228-1263.

3. Corso A, Caberlon S, Pagnucco G, et al. Blood stem cell collections in multiple myeloma: definition of a scoring system. Bone Marrow Transplant. 2000;26(3):283-286.

4. Overdijk MB, Verploegen S, Bogels $M$, et al. Antibody-mediated phagocytosis contributes to the anti-tumor activity of the therapeutic antibody daratumumab in lymphoma and multiple myeloma. MAbs. 2015;7(2):311-321.

5. Overdijk MB, Jansen JH, Nederend M, et al. The therapeutic CD38 monoclonal antibody daratumumab induces programmed cell death via Fcgamma receptor-mediated cross-linking. J Immunol. 2016; 197(3):807-813

6. de Weers M, Tai YT, van der Veer MS, et al. Daratumumab, a novel therapeutic human CD38 monoclonal antibody, induces killing of multiple myeloma and other hematological tumors. J Immunol. 2011;186(3):1840-1848.

7. Krejcik J, Casneuf T, Nijhof IS, et al. Daratumumab depletes CD38+ immune-regulatory cells, promotes T-cell expansion, and skews Tcell repertoire in multiple myeloma. Blood. 2016;128(3):384-394.

8. Adams HC III, Stevenaert F, Krejcik J, et al. High-parameter mass cytometry evaluation of relapsed/refractory multiple myeloma patients treated with daratumumab demonstrates immune modulation as a novel mechanism of action. Cytometry A. 2019;95(3):279289.

9. Casneuf T, Adams HC III, van de Donk N, et al. Deep immune profiling of patients treated with lenalidomide and dexamethasone with or without daratumumab. Leukemia. 2021;35(2):573-584.

10. DARZALEX® (daratumumab) injection, for intravenous use [package insert]. Horsham, PA: Janssen Biotech, Inc. 2020. https://www.janssenlabels.com/package-insert/product-monograph/prescribing-information/DARZALEX-pi.pdf

11. Moreau P, Attal M, Hulin C, et al. Bortezomib, thalidomide, and dexamethasone with or without daratumumab before and after autologous stem-cell transplantation for newly diagnosed multiple myeloma (CASSIOPEIA): a randomised, open-label, phase 3 study. Lancet. 2019;394(10192):29-38.

12. Ma X, Wong SW, Zhou P, et al. Daratumumab binds to mobilized CD34+ cells of myeloma patients in vitro without cytotoxicity or impaired progenitor cell growth. Exp Hematol Oncol. 2018;7:27.

13. Ungerstedt JS, Watz E, Uttervall K, et al. Autologous hematopoietic stem cell transplantation in multiple myeloma and lymphoma: an analysis of factors influencing stem cell collection and hematological recovery. Med Oncol. 2012;29(3):2191-2199.

14. Ings SJ, Balsa C, Leverett D, Mackinnon S, Linch DC, Watts MJ. Peripheral blood stem cell yield in 400 normal donors mobilised with granulocyte colony-stimulating factor (G-CSF): impact of age, sex, donor weight and type of G-CSF used. Br J Haematol. 2006; 134(5):517-525.

15. Shah EE, Young RP, Wong SW, et al. Impact of plerixafor use at different peripheral blood CD34(+) thresholds on autologous stem cell collection in patients with multiple myeloma. Biol Blood Marrow Transplant. 2020;26(5):876-883. 